UDC: 811.111:37 https://doi.org/10.22190/JTESAP2104587U

Original scientific paper

\title{
TEACHING ACADEMIC WRITING IN ENGLISH TO STUDENTS OF ECONOMICS THROUGH CONCEPTUAL METAPHORS
}

\author{
Tatiana Utkina \\ National Research University Higher School of Economics, Russia \\ E-mail: utkinatat30@gmail.com
}

\begin{abstract}
The article addresses EFL students' academic writing competence by fostering and evaluating their writing practices through conceptual metaphors. The research dataset comprised 102 Russian students majoring in economics. The students received the instruction based on the framework of the Conceptual Metaphor Theory during their EAP, ESP and EMI courses in economics. Metaphor Identification Procedure VU University Amsterdam (MIPVU) and the method of metaphoric modeling were used to assess EFL writing competence in economic knowledge domains - knowledge of terms and specific concepts, represented as conceptual metaphors. The statistical analysis did not show significant changes in the writing competence level of students when their EAP and ESP writing was compared. However, statistical differences were revealed in the use of metaphors when the students progressed from their EAP to EMI course and from their ESP to EMI course. The qualitative analysis demonstrated main differences within the conceptual metaphor domains in ESP and EMI writing. On the whole, the results reported here suggest the dynamics of FL writing competence of the Russian students specializing in economics when attending an EAP course, an ESP course and an EMI course in economics at the university.
\end{abstract}

Key words: academic writing, subject-specific competence, conceptual metaphor

\section{INTRODUCTION}

In international universities non-native speakers of English are required to demonstrate their mastery of disciplinary course content as well as academic writing competence by producing "texts that increasingly approximate the norms and conventions of their chosen disciplines, with this expectation peaking at the level of postgraduate study" (Coffin et al.2003, 2). These academic requirements have long been considered to pose a greater challenge to university students in non-English speaking countries when the instruction is delivered in English. That holds true for Russian universities where instructors and administrators strive to create learning opportunities appropriate for academic writing development in the contexts of diverse disciplines.

To focus on the development of writing competence by Russian learners of English in disciplinary settings is an important endeavor because current changes in higher education and academic community are resulting in a more rigorous competition among graduates for career

Submitted January $30^{\text {th }}, 2021$, accepted for publication August $1^{\text {st }}, 2021$

Corresponding author: Tatiana Utkina. Higher School of Economics, Russia. E-mail: utkinatat30@ gmail.com 
positions in academic settings. This means that potential candidates are increasingly expected to provide evidence of their academic proficiency in the form of published peer-reviewed articles in a non-native language (e.g. English).

Academic writing has been the subject of much investigation which acknowledges the importance of knowledge of rhetorical conventions (Kaplan 1966, Matsuda 1997), linguistic knowledge, that is the appropriate use of vocabulary, syntax, and cohesive devices (Pincas 1982), or both rhetorical features and linguistic features (Hinkel 2002), appropriate use of academic writing conventions for academic and publishing purposes (e.g. Langum and Sullivan 2017).

In the pedagogical contexts, academic writing has been investigated within two crucial dimensions: the learning-to-write dimension and the writing-to-learn dimension. In the learning-to-write perspective (e.g. Hyland 2011), foreign language (FL) writers learn to express themselves in writing, for example university students learn to write for professional or academic purposes. By contrast, in the writing-to-learn perspective, FL writers write to learn the language or the learning content (Harklau 2002, Manchón 2009).

In the educational programmes of English for Academic Purposes (EAP), English for Specific Purposes (ESP) and English-medium instruction (EMI), learners are exposed both to writing to learn the language and to writing to learn the learning content. The former approach implies developing writing skills as a means of developing foreign language proficiency. The latter suggests developing writing skills as a means of developing subject-specific vocabulary, including terms and subject-specific concepts. However, these programmes are not designed to provide any well-established writing course in the target language. Little is known what instruction methods are most effective for writers as non-native speakers of English in the disciplinary contexts. The studies of this question are rather fragmented or they have mostly addressed the contexts of English-speaking universities.

One important perspective to approach FL academic writing competence is by applying metaphor to language teaching. Using a metaphor-based teaching strategy is justified for several reasons. Firstly, since the introduction of a theoretical framework by Lakoff and Johnson (1980), metaphor is no longer considered to be a stylistic device. Metaphor is a universal mechanism of thought and language development: "metaphor is the main mechanism through which we comprehend abstract concepts and perform abstract reasoning" and "our metaphor system is central to our understanding of experience and to the way we act on that understanding" (Lakoff 1992, 39-40). According to the contemporary theory of metaphor, metaphors are representations of thinking processes, reflecting how people conceive of and conceptualize the world. Alekseeva and Mishlanova (2016) assumed that if learning is a way from knowledge to understanding, then metaphor is its ultimate objective and the main method to achieve learning outcomes. The authors concluded, that "training in professional activity should be conducted by means of the metaphorical competence, which is defined as a universal ability to provide integrity of speech communication and speech activity" (Alekseeva and Mishlanova 2016, 107).

Secondly, metaphor has been widely recognized as an integral part of FL proficiency, and "highly relevant to second language learning, teaching and testing, from the earliest to the most advanced stages of learning" (Littlemore and Low 2006, 270). Much evidence of the impact of the metaphor use on writing proficiency lies in the domain of English for General purposes and focuses on analyzing linguistic metaphors and their frequency and functions in the written text (e.g. Littlemore et al. 2012, Hashemian and Talebi Nezhad 2007, Kathpalia and Heah 2011). However, little is known about FL 
learners' conceptualization of their subject-specific knowledge, that is, the abstract relationships between concepts underlying metaphorical words used by FL writers.

Finally, most subject-specific language, in particular terms and concepts, is metaphorical by nature (e.g. Herrera and White 2000, McCloskey 1998). The nonliteralness of the language of economics may cause some difficulties for FL learners of economics. Herrera and White (2000) called for learners not to be "shielded" from these difficulties and instructors to find pedagogical implications from different theoretical approaches to stimulate learners to look for underlying interpretations in metaphorical economic terms (Herrera and White 2000, 57).

Despite the vast majority of theoretical and empirical studies of how academic language is acquired and academic writing competence is developed, there are still debates about appropriate approaches to developing subject-specific writing competence in English. The present study set out to test the hypothesis that applying conceptual metaphors in teaching FL learners' subject-specific writing is a strategy that contributes to FL writing development in their EAP, ESP and EMI study of economics.

\section{MATERIALS AND METHODS}

This study is a quantitative and qualitative research in nature. To achieve the aim of this research, 102 Russian learners of English as a foreign language at the Perm campus of the National Research University - Higher School of Economics (HSE) were chosen as the participants of the research. The dataset included: 1) 34 students enrolled for an English for Academic Purposes (EAP) course; 2) 34 students enrolled for an English for Specific Purposes (ESP) course; 3) 34 students enrolled for an English-medium instruction (EMI) course in economics. All the participants of this study majored in economics. All students were taught by the same instructor.

The study incorporated several steps. The first step was designing a conceptual metaphor-based instruction model in the EAP, ESP and EMI study of economics. The students were offered to attend three subsequent university courses, starting from the EAP course, followed by the ESP course, finishing with the EMI course in economics.

During the EAP course (144 academic hours) students were instructed to develop their writing skills as an aid to improve learners' communication skills. Specifically, they might be assigned to make notes for future reference; take down messages from dictation, etc (that is an integrated part of academic listening and reading activities) and write reports, discursive essays, etc.

The ESP study of economics (104 academic hours) was introduced to students with the aim to develop proficiency in foreign language learning and discipline-specific learning with the equal emphasis made on both elements of language and content. This course focused on developing subject-specific vocabulary, including economic terms and specific concepts, reading and listening skills for professional spoken and written communication. Language skills were taught systematically throughout the course. The main purpose of ESP students' essays or reports was to demonstrate learners' mastery of both academic writing skills and disciplinary course content.

The EMI course in economics (54 academic hours) was introduced to students majoring in economics in order to develop proficiency in discipline-specific learning with the emphasis made on content rather than on language. English was used as the language 
of instruction to teach the subject in the curriculum rather than the language. The ultimate aim of this course was to train students as members of professional/ academic communities. In this context, writing was applied as the assessment to check learners' knowledge of the subject.

All these three university courses incorporated metaphor-based instruction in order to develop and evaluate academic writing competence. Conceptual metaphor theory-based instruction was adopted as the framework for teaching disciplinary writing in the current research. Conceptual metaphor theory as a pedagogical approach has proved to encourage students' awareness of the motivated nature of language and foster their engagement and productivity (e.g. Boers and Lindstromberg 2006, Li 2009, Yasuda 2010).

The instruction took into account metaphoricity of economic academic discourse. The students chosen for the current study were consistently exposed to the study material, which is completely authentic with the recommended study books and articles written by native speakers of English. The students were assigned to acquire metaphorical economic terms through listening, reading, speaking and writing activities. For all the activities tasks were specially designed, and the students were guided to approach not-so-obvious concepts of economics through analyzing the interplay between the source and target domains of metaphors and use economic metaphors in the classroom. The students were offered the following tasks: choosing the economic terms from the study material, building up word lists of economic terms, establishing the associations between the metaphorical expression and its more concrete senses, discussing these associations in the classroom.

The second research step was to control and assess the learning process. At the end of their corresponding course, the students were exposed to the International English Language Testing System (IELTS) Academic Module test and academic writing assignments.

The IELTS test was given to the students to identify their FL competence level. The purpose was to make sure that the groups were not of different language competence level. Their test consisted of four sections: Listening, Reading, Writing and Speaking Tests, which reflect their four basic language skills. The test showed their overall performance reported as a single band score, ranging from 5.5 to 8 . The IELTS 5.5-8 bands correspond to CEFR Level B2-Level C1. The average IELTS score ranges from 6.44 to 6.57 , depending on the university course. Table 1 shows the sample composition by gender, age and language level.

Table 1 Gender, age and language level distribution of the sample

\begin{tabular}{|l|c|c|c|c|}
\hline \multirow{2}{*}{$\begin{array}{l}\text { University } \\
\text { course }\end{array}$} & $\begin{array}{c}\text { Number of } \\
\text { students }\end{array}$ & \multirow{2}{*}{ Age } & \multicolumn{2}{|c|}{ IELTS scores } \\
\cline { 4 - 5 } & $34(24 \mathrm{~F}, 10 \mathrm{M})$ & $19-20$ & Range & Average \\
\hline EAP & $34(24 \mathrm{~F}, 10 \mathrm{M})$ & $20-21$ & $5.5-8$ & 6.44 \\
\hline ESP & $34(24 \mathrm{~F}, 10 \mathrm{M})$ & $21-22$ & $5.5-8$ & 6.54 \\
\hline EMI & $102(72 \mathrm{~F}, 30 \mathrm{M})$ & $19-22$ & $5.5-8$ & 6.57 \\
\hline Total & &
\end{tabular}

Three weeks before the end of their corresponding course, the students were given a writing task. This time period was chosen for at least two reasons. The first reason is that it is more reasonable that language skills, which have been recently taught, are approached through ongoing or formative assessment with the main goal to gather information on the extent of learning. The other reason is that ongoing assessment seems to be less pressing for 
the students. The students were assigned to write a discursive essay presenting their personal opinion on economic and financial issues, with $250-300$ word limit. The students were expected to produce their writing output at Level B2 and Level $\mathrm{C} 1$. According to the descriptions of language learners' abilities at Level B2 and Level C1, learners are able to produce argumentative and evaluative essays with "clear, well-structured expositions of complex subjects", with a clear focus on "the relevant salient issues", "with subsidiary points, reasons and relevant examples", and with the evaluation of different ideas (Council of Europe 2001, 62).

Afterwards, their written texts were collected and divided into three corpora, one representing EAP students' writing, one representing ESP students' writing, and one - EMI students' writing. In order to assess the learning outcome, conceptual metaphor analysis was conducted. The first step in this analysis involved identifying metaphorically used words, by using MIPVU methodology (Pragglejaz Group 2007, Steen 2009). How this method works is illustrated in the following sentence, which comes from our data, 'Perhaps, these programmes [governmental support] are created because most economists consider that small firms are the backbone of the economy', one of these lexical units has a more basic meaning than its contextual meaning - 'backbone'. The noncontextual meaning of 'backbone', which is the row of connected bones that go down the middle of the back, is more basic than its contextual meaning - the most important part of an economy. The meaning of 'backbone' in this context can be understood in comparison with its more basic meaning. This lexical unit is marked as being metaphorically used. Following the findings obtained in the studies by Alejo (2010), Sinclair (1991) and Littlemore et al. (2012), we regarded a single word as a metaphorically used unit even if some uses may be recorded in the dictionary as making up a phraseological unit, which, however, may be treated by nonnative speakers in a more compositional way, that is not as one unit. By applying this technique, 398 metaphorical units - economic terms and specific knowledge concepts in economics - were derived from the corpus of essays produced by the students in the EAP course, the ESP study of economics and the EMI study of economics.

At the second step of the conceptual metaphor analysis, the focus was on metaphorical units in the contexts, where the two concepts - target domains or specific knowledge concepts in economics and source domains - are represented based on comparison. Under this approach, the purpose was to reveal the implied conceptual metaphors and group all identified metaphors into basic domain and subdomain levels of conceptual configurations in metaphoric mappings. This may be illustrated by the example from the data. The conceptual metaphor ECONOMY IS A HUMAN BEING is a set of correspondences between the target domain of economy and the source domain of a human being. These correspondences refer to mappings, which represent certain elements of the source domain mapped onto the elements of the target domain. Then the subdomains or sub-metaphors of the conceptual metaphor - ECONOMY IS A HUMAN BEING - may be - STRUCTURE OF ECONOMIC SYSTEM IS STRUCTURE OF A PHYSICAL BODY Or CHANGE IN ECONOMY IS MOVEMENT OF A HUMAN BEING. The essays and the contexts containing metaphors were independently assessed by two independent raters to ensure reliability and validity. The original quotes were benchmarked against the examples of the categories (e.g. Lakoff et al. 1991). In cases of disagreement, the contexts were re-analyzed by both raters.

Finally, the statistical analysis was applied to compute mean values and standard deviations and analyze the pairwise comparisons between the groups. The results of the quantitative and qualitative analysis were interpreted and discussed. 


\section{RESULTS}

The research findings showed that the teaching approach adopted in the current study exerted a positive impact on students' use of disciplinary metaphors in their writing. The study identified both quantitative and qualitative differences in EAP, ESP and EMI students' writing in regard to the FL writers' subject-specific competence viewed through conceptual metaphors.

The research questioned the extent to which there is a significant difference in the level of academic writing competence in the EAP, ESP and EMI courses. To reach the research objective, one-way ANOVA was used. In all of the analyses, it was seen that the assumptions of homogeneity of variance were met. Table 2 includes the mean values and standard deviations of metaphor use in EAP, ESP and EMI writing. It was tested whether the metaphoric density, operationalized as the ratio of the number of metaphors to the total number of words used, was different in EAP, ESP and EMI writing. For better reference, the results in Table 2 are reported in raw scores.

Table 2 Mean values and standard deviations of metaphor use in EAP, ESP and EMI writing

\begin{tabular}{|l|c|c|c|c|c|c|}
\hline Variables & $\begin{array}{c}\text { Number of } \\
\text { words }\end{array}$ & $\begin{array}{c}\text { Number of } \\
\text { metaphors }\end{array}$ & Mean values & SD & F & $\mathrm{p}$ \\
\hline EAP writing & 10273 & 106 & 0.010 & 0.007 & 18.883 & 0.000 \\
\cline { 1 - 5 } ESP writing & 11491 & 102 & 0.009 & 0.006 & & \\
\hline EMI writing & 11213 & 190 & 0.017 & 0.004 & & \\
\hline
\end{tabular}

Table 2 shows significant differences in the use of metaphors in EAP, ESP and EMI writing (the $F$ value is 18.883 and its associated $p$ level is less than 0.01 ). The results indicated there was a higher level of metaphor use in EMI writing, with ESP writing scoring the lowest level of metaphor use. The most remarkable aspect of the data is that the number of metaphors used by the FL writers increased with their subject-specific competence level when they progressed from the EAP to EMI study of economics.

Tables 3 and 4 present mean values and standard deviations of metaphor variables in EAP, ESP and EMI writing. The conceptual metaphor domains were taken from the metaphor analysis of the essays written by EAP, ESP and EMI students. Each group of students was measured on the same variable of metaphor use, having undergone the same writing task. The metaphor related words in the corpora of EAP, ESP and EMI students' writing were categorized according to different source domains they belong to, in particular, a human being (CM 1), water (CM 2), a plant (CM 3), a machine (CM 4), and a building (CM 5).

Significant differences were noted between the means of CM 1 (the $F$ value is 7.865 and its associated $p$ level is less than 0.01) and CM 2 (the $F$ value is 5.815 and its associated $p$ level is less than 0.01), independent of the writing variable, as determined by one-way ANOVA (Table 4). In general, the students in the EAP, ESP and EMI courses predominantly construed economic and financial concepts through a more physical domain of Human beings (CM 1). 
Table 3 Mean values and standard deviations of metaphor variable in EAP, ESP and EMI writing

\begin{tabular}{|l|c|c|}
\hline EAP writing & M & SD \\
\hline Variables & 0.785 & 0.318 \\
\hline CM 1 & 0.000 & 0.000 \\
\hline CM 2 & 0.048 & 0.126 \\
\hline CM 3 & 0.100 & 0.259 \\
\hline CM 4 & 0.067 & 0.205 \\
\hline CM 5 & \multicolumn{2}{|c|}{} \\
\hline ESP writing & M & SD \\
\hline Variables & 0.516 & 0.416 \\
\hline CM 1 & 0.029 & 0.171 \\
\hline CM 2 & 0.054 & 0.195 \\
\hline CM 3 & 0.233 & 0.379 \\
\hline CM 4 & 0.167 & 0.298 \\
\hline CM 5 & \multicolumn{2}{|c|}{} \\
\hline EMI writing & M & SD \\
\hline Variables & 0.496 & 0.253 \\
\hline CM 1 & 0.121 & 0.203 \\
\hline CM 2 & 0.104 & 0.133 \\
\hline CM 3 & 0.188 & 0.226 \\
\hline CM 4 & 0.089 & 0.129 \\
\hline CM 5 & \multicolumn{2}{|c|}{} \\
\hline
\end{tabular}

Table 4 One-way ANOVA test of the metaphor variable

\begin{tabular}{|l|c|c|c|c|c|}
\hline Variables & CM 1 & CM 2 & CM 3 & CM 4 & CM 5 \\
\cline { 1 - 5 } EAP writing & $\mathrm{F}=7.865$, & $\mathrm{F}=5.815$, & $\mathrm{F}=1.348$, \\
$\mathrm{ySP}$ writing & $\mathrm{p}=0.000$ & $\mathrm{p}=0.004$ & $\begin{array}{c}\mathrm{F}=1.812, \\
\mathrm{p}=0.169\end{array}$ & $\begin{array}{c}\mathrm{F}=1.920, \\
\mathrm{p}=0.152\end{array}$ \\
\cline { 1 - 5 } EMI writing &
\end{tabular}

Visual examination of the means (Table 3) suggests that the highest level of CM 1 was demonstrated by EAP students, and that the other two groups of students had lower average levels of using CM 1 than EAP students. With regard to CM 2, EMI students showed its highest level, whereas EAP students did not view the economy in terms of water. There were no statistically significant differences between the means of CM 3, CM 4 and CM 5 metaphors, independent of the writing variable ( $p$ level is more than 0.05).

Games-Howell post-hoc test was conducted to verify the results and clarify the differences between EAP, ESP and EMI writing in all metaphor types and specifically in CM 1 and CM 2 variables. See Table 5 for group comparisons based on Games-Howell post-hoc comparisons. 
Table 5 Multiple comparison of means - Games-Howell post-hoc test

\begin{tabular}{|l|c|l|l|}
\hline Variables & $\begin{array}{c}\text { EAP-ESP writing } \\
\text { Diff }\end{array}$ & \multicolumn{1}{|c|}{$\begin{array}{c}\text { ESP-EMI writing } \\
\text { Diff }\end{array}$} & $\begin{array}{c}\text { EAP-EMI writing } \\
\text { Diff }\end{array}$ \\
\hline All metaphors & $0.001006, p=0.776$ & $-0.00806, p=0.001$ & $-0.00706, p=0.001$ \\
CM 1 & $0,269374, p=0,008$ & $0,019678, p=0,9$ & $0,289052, p=0,001$ \\
CM 2 & $-0,02941, p=0,572$ & $-0,09216, p=0,108$ & $-0,12157, p=0,002$ \\
\hline
\end{tabular}

Overall, the results from Games-Howell post-hoc test suggest that except EAP-ESP writing, all other pairwise comparisons indicate statistically significant differences. Regarding CM 1 variable, there were statistically significant differences between EAP and ESP writing and between EAP and EMI writing, with EAP writing showing a significantly higher average score in the pairwise comparison between EAP and EMI writing. As regards CM 2 variable, there was a statistically significant difference between the means of EAP and EMI writing, with EMI writing having a higher average score of metaphor use. There were no significant mean differences: 1) between ESP and EMI writing in the use of CM 1;2) between EAP and ESP writing in the use of CM 2;3) between ESP and EMI writing in the use of CM 2. It is possible that parts of the nonsignificant findings may be due to the small sample size.

The results of the qualitative analysis showed how students might conceptualize specific knowledge domain of economics and whether their conceptualization patterns would change from one writing level to another (Table 6).

Table 6 Conceptualization patterns in EAP, ESP and EMI writing

\begin{tabular}{|l|l|l|l|}
\hline $\begin{array}{l}\text { Conceptual } \\
\text { metaphor }\end{array}$ & EAP writing & ESP writing & EMI writing \\
\hline $\begin{array}{l}\text { ECONOMY IS A } \\
\text { (CM 1) }\end{array}$ & $\begin{array}{l}\text { Structure of a } \\
\text { physical body } \\
\text { Movement } \\
\text { Positive } \\
\text { interpersonal } \\
\text { relationships } \\
\text { Health/disease }\end{array}$ & $\begin{array}{l}\text { Structure of a physical } \\
\text { body } \\
\text { Movement } \\
\text { Negative interpersonal } \\
\text { relationship } \\
\text { Health/disease }\end{array}$ & $\begin{array}{l}\text { Structure of a physical } \\
\text { body } \\
\text { Movement } \\
\text { Positive and negative } \\
\text { interpersonal relationships } \\
\text { Health/disease/treatment }\end{array}$ \\
\hline $\begin{array}{l}\text { ECONOMY IS } \\
\text { WATER (CM 2) }\end{array}$ & - & Flow & $\begin{array}{l}\text { Flow } \\
\text { Move }\end{array}$ \\
\hline $\begin{array}{l}\text { ECONOMY IS A } \\
\text { PLANT (CM 3) }\end{array}$ & Growth of a plant & $\begin{array}{l}\text { Parts of a plant } \\
\text { Growth of a plant }\end{array}$ & Growth of a plant \\
\hline $\begin{array}{l}\text { MACONOMY IS A } \\
\text { (CM 4) }\end{array}$ & $\begin{array}{l}\text { Parts of a machine } \\
\text { Functioning of a } \\
\text { machine }\end{array}$ & Parts of a machine & $\begin{array}{l}\text { Parts of a machine } \\
\text { Maintaining a machine }\end{array}$ \\
\hline $\begin{array}{l}\text { ECONOMY IS A } \\
\text { BUILDING } \\
\text { (CM 5) }\end{array}$ & $\begin{array}{l}\text { Structure of a } \\
\text { building } \\
\text { Stability of a } \\
\text { building }\end{array}$ & $\begin{array}{l}\text { Structure of a building } \\
\text { Stability of a building }\end{array}$ & $\begin{array}{l}\text { Structure of a building } \\
\text { Stability of a building } \\
\text { Maintaining a building }\end{array}$ \\
\hline
\end{tabular}

As shown in Table 6, there were both commonalities and differences in the way the EAP, ESP and EMI students chose conceptual metaphors when they discussed and 
expressed their opinions on economic issues in writing. The key differences within the conceptual metaphor domains were observed: 1) in CM 1 for ESP and EMI writing; 2) in CM 2 for EMI writing; 3) in CM 3 for ESP writing; 4) in CM 4 for EAP and EMI writing; 5) in CM 5 for EMI writing.

\section{DISCUSSION}

The present study was designed to develop and assess Russian students' writing competence in the EAP, ESP and EMI courses by applying conceptual metaphors. The research findings showed the correlation between the practice of using metaphors and metaphor production in subject-specific writing by students at their different courses.

The statistical analysis showed the extent to which the metaphor use differed in EAP, ESP, EMI writing and whether there were statistically significant changes in the level of writing quality when students proceeded from their EAP to ESP and EMI course in economics. The results indicated that the FL writers' metaphor use increased when they progressed from the EAP to EMI study of economics. Although the changes in metaphor production were not significant between EAP and ESP writing, the metaphor use increased from ESP writing to EMI writing and from EAP writing to EMI writing. These findings support the work of other studies in this area linking FL learners' competence levels in their specific knowledge domains and instructional approaches to teaching major disciplines in the target language (e.g. Tarnopolsky and Vysselko 2014). In particular, it was claimed that FL learners developed their subject-specific competence in English when they moved from their ESP course in the first two years to a more advanced ESP course in the subsequent years. The present results seem to be consistent with other researches that recognized the importance of metaphor in economic terminology (e.g. Langer 2015). It is stressed that students of economics could approach not-so-obvious concepts of economics through explicating the conceptual mappings of metaphors.

Although limited in scope, this study also revealed some interesting insights into EFL writing competence developed by students in their EFL studies of economics. First, the students in the EAP, ESP and EMI courses predominantly viewed economic and financial concepts through a more physical domain of Human beings. EAP and ESP writing and EAP and EMI significantly differed on the use of ECONOMY IS A HUMAN BEING metaphors, with EAP having a higher average score in both cases. This may be partly attributed to the EAP instruction, when students were expected to develop their communication skills in English for General and Academic Purposes rather than Specific Purposes. This may suggest that the EAP students made sense of economic phenomena in human terms on the basis of their own motivations, goals, activities and characteristics.

Second, there were no significant mean differences between ESP and EMI writing in the use of ECONOMY IS A HUMAN BEING. Besides, there were no significant mean differences between EAP and ESP writing and between ESP and EMI writing in the use of ECONOMY IS WATER. Furthermore, it is not surprising that the study did not yield any significant differences in EAP, ESP and EMI writing in the use of ECONOMY IS A PLANT, ECONOMY IS A MACHINE and ECONOMY IS A BUILDING. A possible explanation may be that the metaphor models appeared to be shared by the students throughout three courses only in cases when metaphors may have been linked to more universal experiential domains. This may be explained by the students' common EFL background. Another general 
observation is that the students' choice of metaphors could be attributed to the students' discipline-related experience that accords with the educational programme which offers fundamental training in the modern economic theory, a wide range of mathematical disciplines, the most recent data-processing technologies, statistics, econometrics, as well as work with advanced software packages (Educational Programme 2016).

Finally, in both quantitative and qualitative terms, the key differences within the conceptual metaphor domains were observed in ESP and EMI writing. As regards ESP writing, FL writers tend to avoid using metaphor for the reason that they have difficulty in acquiring the conceptual system of a foreign language (Hashemian and Talebi Nezhad, 2007, Kathpalia and Heah 2011). According to Hashemian and Talebi Nezhad (2007), FL learners wrote with the formal structures of the target language but in terms of their L1 conceptual system and showed "no sign of the conceptual system in English" (Hashemian and Talebi Nezhad 2007, 51), however, their command of the English conceptual metaphors could be improved considerably after their exposure to FL concepts during the process of FL teaching/learning. Another important finding of the current study was that the ESP students demonstrated a shift from a balanced distribution of the domains of PLANT, MACHINE and BUILDING toward a number of machine- and building-related terms. This way, the students facilitated their understanding of economic processes that could be managed by specialists in economics. Apart from this change, they started to see economic processes as part of the external world by referring to inanimate nature. At this stage of their studies, the students showed their subject-specific writing competence development by using a greater variety of subject-specific vocabulary involving metaphors. However, their metaphor production was still restricted to conventionalized metaphors, which can prove students' hesitations in acquiring the conceptual system of a second language simultaneously with subject-specific content.

When attending the English-medium instruction course in economics, the students appeared to be more competent in metaphor production. The texts produced by the EMI students demonstrated a sharp increase in the use of metaphors. The observed increase could be attributed to the fact that the EMI writers were exposed to writing performance based on example target texts and their specific aspects including text type, register, subject-specific and functional language. Another possible explanation for this may be that it is at this level of study that FL writers try to improve their subject-specific communication skills and understand the economy through metaphor. This may well coincide with the fact that this is the level where they make progress in their writing competence in the academic discourse which is characterized by high metaphoricity or metaphoric density (Steen et al. 2010). The distribution of the source domains of PLANT, MACHINE, BUILDING and WATER became more even. The students showed their more advanced competence by selecting certain preferred conceptual metaphors to describe the complexity of the economic system in more detail as well as by choosing metaphorical expressions, demonstrating a switch from conventionalized to creative ones.

Nevertheless, a number of limitations have to be acknowledged and further research would be essential to determine whether these constraints can be removed. In particular, a limitation of the study was a relatively small sample size and a small writing sample provided by each participant. For this reason, the findings cannot be generalized. Moreover, despite the explicit teaching of conceptual metaphors in each course, students' use of metaphor in writing may be influenced by other factors (e.g. cognitive style, L1 interference), whose further investigation may be beneficial. Last, it is beyond the scope 
of this study to examine the way EFL learners process metaphorical expressions in their EAP, ESP and EMI studies of economics.

\section{CONCLUSION}

Overall, this study explored the effects of using conceptual metaphor-based strategies in developing FL learners' academic writing competence in the EAP, ESP and EMI courses at a Russian university. Its results contributed to the findings obtained in the few studies that examined FL writing related to subject-specific competence (not language competence) in higher education. The findings reported here revealed the dynamics of FL writing competence of the Russian students specializing in economics when attending the EAP course, the ESP course and the EMI course in economics at the university.

The study identified both quantitative and qualitative differences in EAP, ESP and EMI students' writing in regard to the FL writers' subject-specific competence viewed through conceptual metaphors. The statistical analysis showed that there were statistically significant changes in the level of writing competence when students proceeded from their EAP to ESP and EMI course in economics. Although the changes in the metaphor use were not significant between EAP and ESP writing, the metaphor use increased from ESP writing to EMI writing and from EAP writing to EMI writing. The in-depth analysis showed that the use of metaphors within the conceptual metaphor domains exerted some influence on ESP and EMI writing. Despite the lack of the explicit English language and writing instruction in the EMI course in economics, the students demonstrated writing competence which approximated the academic writing in economics, with the distribution of metaphor models following the pattern of models in the English academic texts on economics (Utkina 2011).

Further research should be undertaken to investigate: whether EFL learners' writing competence improves from the EAP to ESP, to EMI course, when academic writing in the target language is explicitly taught; whether the knowledge of economics in students' native language influences EFL learners' writing competence in their EAP, ESP and EMI studies of economics.

\section{REFERENCES}

Alejo, Rafael. "Making sense of phrasal verbs: a cognitive linguistics account." In Applied cognitive linguistics in second language learning and teaching, edited by Littlemore Jeannette, and Constanze Juchem-Grundmann, 50-71. AILA Review, 2010.

Alekseeva, Larisa, and Svetlana Mishlanova. Formirovanye metaforicheskoy kompetentsii [Formation of the metaphorical competence]. Vestnik permskogo universiteta. Rossiyskaya i zarubezhnaya filologiya, 4(36) (2016): 98-107.

Boers, Frank, and Seth Lindstromberg. "Cognitive linguistic applications in second or foreign language instruction: Rationale, proposals, and evaluation." In Cognitive linguistics: Current applications and future perspectives, Gitte Kristiansen, Michel Achard, René Dirven, and Francisco J. Ruiz de Mendoza Ibáñez, 305-355. Berlin, New York: Mouton De Gruyter, 2006.

Coffin, Caroline, Mary Jane Curry, Sharon Goodman, Ann Hewings, Theresa M. Lillis, and Joan Swann. Teaching academic writing: A toolkit for higher education. London: Routledge, 2003. 
Council of Europe. Common European Framework of Reference for Languages: Learning, Teaching and Assessment. Strasbourg, 2001.

Educational Programme. Accessed August 21, 2016. http://www.hse.ru/edu/courses/ 94100352.html

Harklau, Linda. "The role of writing in classroom second language acquisition." Journal of Second Language Writing 11 (2002): 329-350.

Hashemian, Mahmood, and Mohammad Reza Talebi Nezhad. "The development of conceptual fluency and metaphorical competence in L2 learners." Linguistik online 30(1/06) (2013): 41-56.

Herrera, Honesto, and Michael White. "Cognitive linguistics and the language learning process: A case from Economics." Estudios Ingleses de La Universidad Complutense (8) (2000): 55-78.

Hinkel, Eli. Second Language Writers' Text: Linguistic and Rhetorical Features. Mahwah, NJ: Lawrence Erlbaum Associates, 2002.

Hyland, Ken. "Learning to write: Issues in theory, research and pedagogy." In Learningto-write and writing-to-learn in an additional language, edited by Rosa M. Manchón, 17-35. John Benjamins, 2011.

Kaplan, Robert B. "Cultural thought patterns in intercultural education." Language Learning 16(1) (1966): 1-20.

Kathpalia, Sujata S., and Heah Lee Hah Carmel. "Metaphorical competence in ESL student writing." RELC Journal 42(3) (2011): 273-290.

Lakoff, George, and Mark Johnson. Metaphors We Live By. Chicago: University of Chicago Press, 1980.

Lakoff, George, Jane Espenson, and Alan Schwartz. "Master Metaphor List," October 1991, <https://meta-guide.com/data/data-processing/computational-metaphorics/ master-metaphor-list> (21 December 2020).

Lakoff, George. "The contemporary theory of metaphor." In Metaphor and Thought, 2nd ed., edited by Andrew Ortony, 1-50. Cambridge University Press, 1992.

Langer, Tomáš. "Metaphors in economics: Conceptual mapping possibilities in the lectures of economics." Procedia Economics and Finance 25 (2015): 308-317.

Langum, Virginia, and Kirk P.H.Sullivan. "Writing academic English as a doctoral student in Sweden: Narrative perspectives." Journal of Second Language Writing 35 (2017): 20-25.

Li, Thomas Fuyin. Metaphor, image, and image schemas in second language pedagogy: The acquisition of metaphorical expressions, idioms, and proverbs by Chinese learners of English. Koln: Lambert Academic, 2009.

Littlemore, Jeannette, and Graham Low. "Metaphoric competence, second language learning, and communicative language ability." Applied linguistics 27(2) (2006): 268-294.

Littlemore, Jeannette, Tina Krennmayr, James Turner, and Sarah Turner. "Investigating figurative proficiency at different levels of second language writing." Research Notes 47 (2012): 14-23.

Manchón, Rosa M. "Broadening the perspective of L2 writing scholarship: The contribution of research on foreign language writing." In Writing in foreign language contexts: Learning, teaching, and research, edited by Rosa M. Manchón, 1-19. Multilingual Matters, 2009.

Matsuda, Paul Kei. "Contrastive rhetoric in context: A dynamic model of L2 writing." Journal of Second Language Writing 6(1) (1997): 45-60. 
McCloskey, Donald N. The Rhetoric of economics. University of Wisconsin Press, 1998.

Pincas, Anita. Teaching English Writing. Macmillan, 1982.

Pragglejaz Group. "MIP: A method for identifying metaphorically used words in discourse." In Metaphor and Symbol, edited by Raymond W. Gibbs, Jr., 22(1), 1-39. Routledge, 2007

Sinclair, John. Corpus, Concordance, Collocation. Oxford: Oxford University Press, 1991.

Steen, Gerard J. "From linguistic form to conceptual structure in five steps: Analyzing metaphor in poetry." In Cognitive poetics: Goals, gains and gaps, edited by Geert Brône, and Jeroen Vandaele, 197-226. Mouton de Gruyter, 2009.

Steen, Gerard, Alleta G. Dorst, J. Berenike Herrmann, Anna A. Kaal, Tina Krennmayr, and Tryntje Pasma. A method for linguistic metaphor identification. John Benjamins Publishing Company, 2010.

Tarnopolsky, Oleg, and Andriy Vysselko. "Mini-courses on economic disciplines in an advanced ESP course for university students of economics." The Journal of Teaching English for Specific and Academic Purposes 2 (1) (2014): 45-59. Accessed March 20, 2016. http://espeap.junis.ni.ac.rs/index.php/espeap/issue/view/3.

Utkina, Tatiana. Metaphor in English academic discourse in economics. September 2011, <http://www.english.su.se/polopoly_fs/1.31643.1320940006!/Stockholm_2011_Meta phor_Festival_ABSTRACTS_Vers_1_3.pdf> (15 January 2012).

Yasuda, Sachico. "Learning phrasal verbs through conceptual metaphors: A case of Japanese EFL learners.” TESOL Quarterly 44(2) (2010): 250-273. 